\title{
Temperature integrity and exposure of vaccines to suboptimal temperatures in cold chain devices at different levels in three states of India
}

\author{
Manoja Kumar Das ${ }^{1 *}$ D, Narendra Kumar Arora ${ }^{1}$, Thomas Mathew², Bhadresh Vyas ${ }^{3}$, Salam Kabita Devi ${ }^{1}$ and
} Abhishek Yadav'

\begin{abstract}
Objective: To document the temperature integrity at the vaccine storage devices at various levels in three states of India.

Methods: A total of 213 health facilities including 196 facilities (district and sub-district levels) from 27 select districts and 17 division or state level vaccine stores in three states were included. At these facilities, temperature in 223 vaccine storage devices was recorded for at least 7 consecutive days using electronic temperature datalogger.

Results: During the observation period, overall the vaccines were exposed to temperature $<0^{\circ} \mathrm{C}$ for $14.8 \%$ of the storage time with 8.6, 6.7 and $18 \%$ at state/division, district and sub-district vaccine stores, respectively. The vaccines were also exposed to temperature $>8{ }^{\circ} \mathrm{C}$ for $6.6 \%$ of the storage time including $1.3,13$ and $5.1 \%$ at state/ division, district and sub-district vaccine stores, respectively. Continuous episodes of temperature deviation for 45 min or longer to $<0^{\circ} \mathrm{C}$ and $>8^{\circ} \mathrm{C}$ was observed in 7.2 and $6.4 \%$ of the observation period, respectively. These temperature deviations were not captured by the routine temperature monitoring practice.
\end{abstract}

Conclusion: The vaccines were exposed to freezing temperature for a considerable period at all level stores, which was more than the exposure to higher temperature. To ensure vaccine potency and immunogenicity, stringent temperature integrity maintenance is needed at all levels.

Keywords: Cold chain, Vaccines, Temperature maintenance, Temperature excursion, Freezing, Datalogger

\section{Background}

Vaccination is one of the most cost-effective public health interventions in twenty-first century [1]. Vaccines are averting millions of deaths and sequelae due to diseases globally and have achieved smallpox eradication, poliomyelitis control and now aiming for measles eradication. Vaccines are temperature sensitive products and

\footnotetext{
* Correspondence: manoj@inclentrust.org

${ }^{1}$ The INCLEN Trust International, F1/5, Okhla Industrial Area, Phase 1, New Delhi 110020, India

Full list of author information is available at the end of the article
}

requires storage within narrow temperature range (usually $2-8{ }^{\circ} \mathrm{C}$ ) during storage and transfers to preserve potency [2]. Some vaccines like oral polio vaccine (OPV) and rotavirus vaccine may be stored at $-20{ }^{\circ} \mathrm{C}$ at bulk stores [3]. All vaccines are usually damaged by cumulative exposure to temperatures above $+8^{\circ} \mathrm{C}$. Vaccine vial monitor (VVM) containing a heat-sensitive material indicate the cumulative heat exposure and guide use of the vaccine. Exposure to freezing temperatures $\left(<0{ }^{\circ} \mathrm{C}\right)$ is equally damaging for the freeze-sensitive vaccines like diphtheria-pertussis-tetanus (DPT), liquid pentavalent 
vaccine (LPV), tetanus toxoid (TT), hepatitis A and B, human papillomavirus (HPV), meningitis $\mathrm{C}$, pneumococcal conjugate vaccine (PCV), cholera, influenza, haemophilus influenza b (Hib), and inactivated poliovirus (IPV) making them inactive [4]. Apart from losing potency, administration of frozen vaccines may cause some adverse events [3]. Detection of exposure to freezing is challenging, as there is no marker currently available and the shake test is not commonly practiced by cold chain handlers and vaccinators $[5,6]$. For shake test, the vaccine vial is vigorously shaken and placed inverted on a flat surface and examined for the physical changes, and the extent of sedimentation after $30 \mathrm{~min}$. The presence of granular forms or floccules when shaking, or the formation of a sediment at the bottom of the container within 30 min, with clear liquid above, suggest that the vaccine has been frozen [7, 8]. The Universal Immunization Programme (UIP) of India targets about 26 million infants, 100 million children aged $1-5$ years and 30 million pregnant women annually [3]. The UIP currently delivers vaccines against 13 vaccine-preventable diseases to children and pregnant women [3]. The cold chain in India is a fivetier storage system with about 26,388 cold chain points or vaccine stores (VSs), including the government medical supply depots (GMSDs) $(n=4)$, state VSs $(n=53)$, divisional VSs $(n=110)$, district VSs $(n=666)$ and the subdistrict VSs $(n=25,555)$ at community health centers $(\mathrm{CHCs})$ and primary health centers (PHCs) [9]. At the GMSDs, the vaccines are stored in cold rooms, walk-in coolers (WICs) and walk-in freezers (WIFs). At state and division VSs, the vaccines are usually stores in WICs, icelined refrigerators (ILRs) and WIFs. At district and subdistrict (CHCs and PHCs) VSs, the vaccines are stored in ILRs. The cold rooms, WICs and ILRs are expected to maintain the optimum temperature $\left(+2\right.$ to $\left.+8^{\circ} \mathrm{C}\right)$ for vaccine storage. The WIFs and deep freezers (DFs) are expected to maintain the optimum temperature $(-15$ to $-25^{\circ} \mathrm{C}$ ) for long-term vaccine storage. The vaccines are transferred in cold boxes of various sizes (between the VSs) and vaccine carriers (to outreach sessions) with icepacks to maintain temperature in +2 to $+8^{\circ} \mathrm{C}$ range. The vaccines and related supplies are handled by cold chain handlers at the cold chain points. The cold chain equipment are maintained by cold chain technicians.

Several studies from India reported exposure of vaccines to high temperatures [10-12]. The literature reported exposure of vaccines to freezing temperatures at vaccine stores for $10-33.7 \%$ in developing countries and $6.4-22.5 \%$ in developed countries [13, 14]. In India, a study across ten states informed about frequent exposure of the vaccines to freezing temperature at state compared to district, division and sub-district VSs [15]. This study was conducted to assess the available cold chain space and vaccine temperature integrity in three states of India for new vaccine introduction. This paper presents the data related to the temperature integrity at the cold chain points.

\section{Methods \\ Study design and setting}

This cross-sectional study was undertaken in three states of India: Bihar, Gujarat and Kerala during 2014-15. The states were purposively selected representing three different levels of routine immunization coverage (lowest, Bihar $49 \%$, moderate, Gujarat $56.6 \%$ and highest, Kerala $81.5 \%$ according to Coverage Evaluation Survey 2009), governance and geography [16]. In each state one-third districts were included. Thus, in Bihar, 13 of 38 districts, in Gujarat, 9 of 26 districts and in Kerala, 5 of 14 districts were randomly selected, ensuring at least one district per division. In each selected district, seven VSs were selected through a multistage process based on distance from the district VS, as shown in Fig. 1. The state and district immunization program teams were consulted for selection of the districts and facilities in the districts. Additionally, in each state, all the division and state VSs were included and the WIC and ILR (used for vaccine storage) were selected for temperature monitoring.

\section{Temperature recording at stores}

The study followed WHO protocol for temperature monitoring in the vaccine cold chain [17]. We used LogTag-Trix 8 data loggers (range $-40^{\circ} \mathrm{C}$ to $+85^{\circ} \mathrm{C}$; precision $\pm 0.5^{\circ} \mathrm{C}$ ) to record the temperatures (LogTag Recorders, Auckland, New Zealand) every $15 \mathrm{~min}$ [18]. The data logger battery and memory could record 8000 readings continuously. Temperature monitoring units $(n=$ 145) containing one datalogger and two DPT vials (shake test negative) were placed inside the WICs, ILRs and others devices storing the vaccines at these facilities for at least 1 week. The research staff installed and removed the dataloggers for each device. For each cold chain device, the datalogger ID, installation and removal time, position of the data logger, thermometer availability, ice deposit on walls, gasket and door seal status at installation and removal were documented. The temperature chart recorded by cold chain handler (for the 1 week observation period and past 3 months) and verifications by the medical officer in-charge (from the registers) were documented at the time of logtag removal. One freeze sensitive vaccine (DPT/TT/HBV/ LPV) from each box stored in the ILR and each rack of WIC (2-3 per ILR/WIC) were checked for freezing by shake test. All the dataloggers were transported to central coordinating office along with the filled data forms. The readings from the data loggers were downloaded using the dedicated software and exported into excel, which contained date and time stamp for each temperature record. 


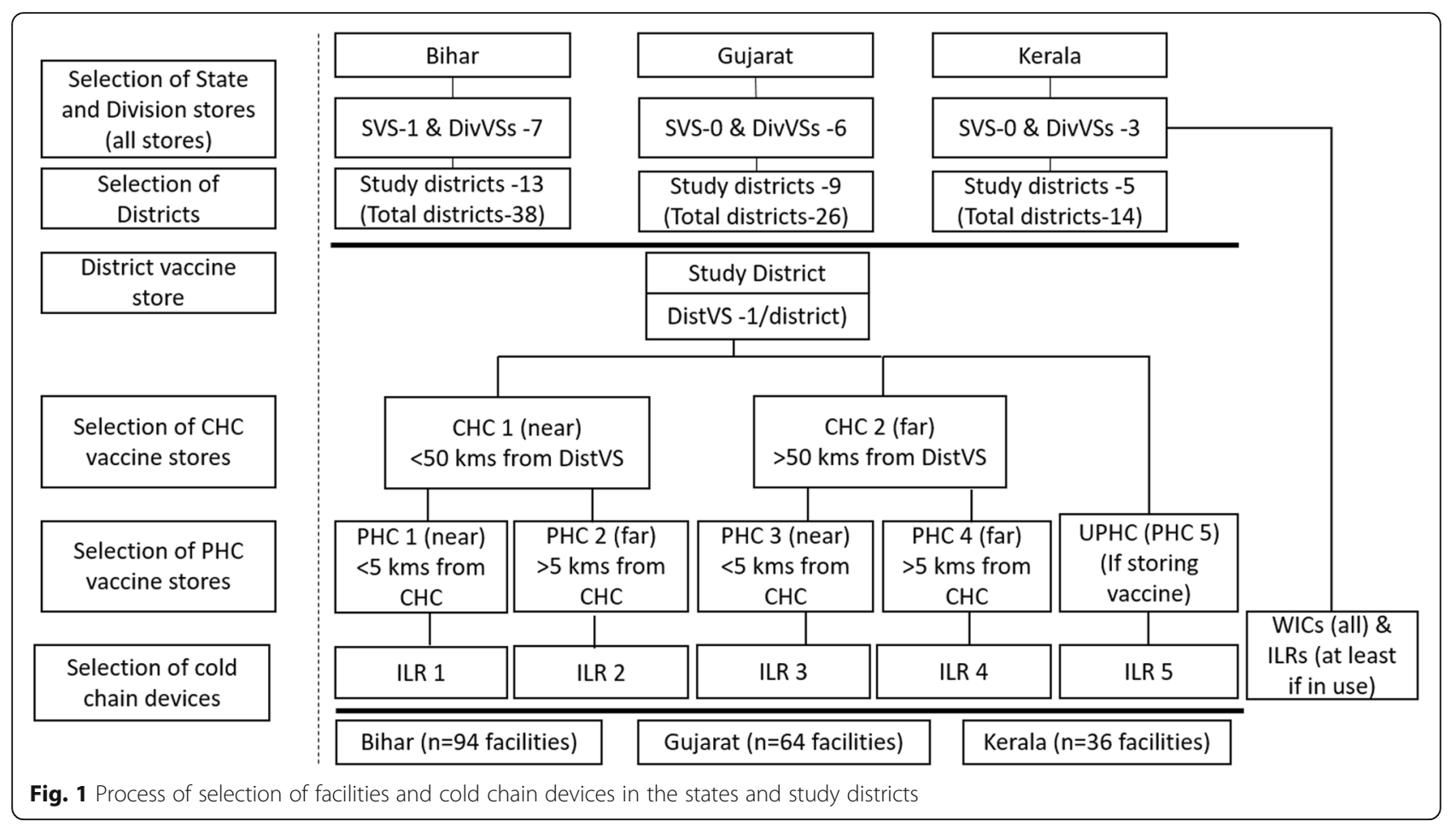

\section{Data analysis}

The first and last data points for the data loggers were excluded, as these might be representing the environmental temperature at placement and removal time. The exposure of vaccines to temperatures < $0{ }^{\circ} \mathrm{C}, \geq 0{ }^{\circ} \mathrm{C}$ to $<2{ }^{\circ} \mathrm{C}, \geq 2{ }^{\circ} \mathrm{C}$ to $\leq 8{ }^{\circ} \mathrm{C}$ and $>8{ }^{\circ} \mathrm{C}$ as proportions of observation period were estimated. Lower post-immunization IgG responses to the DTP vaccines (both acellular and whole cell pertussis antigens) in murine model has been reported on exposure to freezing at $-3{ }^{\circ} \mathrm{C}$ for $24 \mathrm{~h}$ [19]. Thus, the exposure to temperatures $<0{ }^{\circ} \mathrm{C}$ were further segregated to $<-3{ }^{\circ} \mathrm{C}$ and $\geq-3{ }^{\circ} \mathrm{C}$ to $0^{\circ} \mathrm{C}$ to document the risk of freezing. It was observed that after opening of the ILRs (with the logtags inside), the temperature increased and reached to preopening range after $15-30 \mathrm{~min}$. Thus continuous episodes (periods with more than two consecutive readings by a data logger in the same range, for $\geq 45 \mathrm{~min}$ ) of temperature excursion (remaining below $0^{\circ} \mathrm{C}$ or above $8^{\circ} \mathrm{C}$ ), segregated for different durations $(<1 \mathrm{~h},>1-9 \mathrm{~h}$ and $\geq 10 \mathrm{~h})$ were also calculated. The duration of temperature maintenance in the devices were estimated for different types of devices (WICs, ILRs and others) and levels of vaccine stores (state, division, district and sub-district). The data for state and division VSs were pooled, as there was no state store in Gujarat and Kerala. Descriptive statistics measures were calculated using Microsoft Excel and STATA version 12 (StataCorp LLC, Texas, USA).

\section{Approvals}

Administrative approvals from the appropriate national and state health authorities and ethical approval from INCLEN institute ethics committee (protocol no IIEC006) were obtained.

\section{Results}

The temperature recordings from 196 facilities and 218 devices were received. The recordings from 5 ILRs (from 3 PHCs and 2 District VSs) were less than 7 complete days and excluded from analysis. The temperature records for 59,039 h from 213 devices from 191 facilities were analysed. Table 1 shows the distribution of the types of facilities and devices. At 4 PHCs, non-ILR devices (domestic refrigerator, $n=1$ and cold boxes, $n=3$ ) were used for vaccine storage, due to temporary breakdown of ILRs.

\section{Temperature maintenance at vaccine stores}

As shown in Table 2, during the observation period, $75.4 \%$ (95\% CI: $60.8,89.1 \%$ ) of the state and division VSs; $71.1 \%$ (95\% CI: 55.6, 83.1\%) of the district VSs and $56.7 \%$ (95\% CI: 50.2, 63.1\%) of the sub-district (CHCs/ $\mathrm{PHCs}$ ) VSs maintained temperature in the desired range. The temperature dipped to sub-zero range for $8.5 \%$ (95\% CI: $1,17.1 \%$ ), $7.4 \%$ (95\% CI: 6.3, 8.4\%) and $17.7 \%$ (95\% CI: $11.9,22 \%)$ of the observation period at the state/division, district and sub-district VSs respectively. The temperature also crossed above $8{ }^{\circ} \mathrm{C}$ in $5.2 \%(95 \%$ CI: $1,11.3 \%), 10.1 \%$ (95\% CI: $3.8,16.3 \%)$ and 5.4\% (95\% 
Table 1 Description of vaccine stores and cold chain devices included for temperature monitoring

\begin{tabular}{lllllll}
\hline Level/Devices & & \multicolumn{3}{l}{ States } & Total \\
\cline { 3 - 5 } & & Bihar & Gujarat & Kerala & \\
\hline Level of stores & State VS & 1 & 0 & 0 & 1 \\
& Division VS & 7 & 6 & 3 & 16 \\
& District VS & 10 & 9 & 5 & 24 \\
& CHC/PHC & 76 & 49 & 30 & 155 \\
& Total & 94 & 64 & 36 & 196 \\
Type of cold chain devices & WIC & 10 & 6 & 4 & 20 \\
& ILR & $95^{\text {a }}$ & 61 & 38 & 189 \\
& Refrigerator & 1 & 0 & 0 & 1 \\
& Cold box & 3 & 0 & 0 & 3 \\
& Total & 109 & 67 & 42 & 218
\end{tabular}

VS Vaccine store, CHC Community health centre, $P H C$ Primary health centre, ILR Ice lined refrigerator, WIC Walk-in cooler, Refrigerator Domestic refrigerator

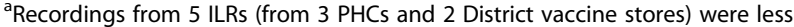
than 7 complete days and excluded from analysis

CI: 5.1, 5.6\%) of the observation period at the state/division, district and sub-district VSs respectively. The temperature fluctuated widely, from $-33^{\circ} \mathrm{C}$ to $+35^{\circ} \mathrm{C}$ in the devices. The temperature deviation to both extremes $\left(<0{ }^{\circ} \mathrm{C}\right.$ and $\left.>8{ }^{\circ} \mathrm{C}\right)$ was observed at $19.7 \%$ of the devices (state/division- $15 \%$, district- $12.9 \%$ and sub-district$21.9 \%)$. The vaccines were exposed to sub-zero temperatures for longer period at the state/division and subdistrict VSs and pooled for all levels, than exposure to > $8{ }^{\circ} \mathrm{C}$. The vaccines spent sizable proportions of time at $<$ $-3{ }^{\circ} \mathrm{C}$ (freezing temperature for many freeze-sensitive vaccines) at all levels of facilities (2.9 to $7.2 \%)$ and in all types of devices ( 0.4 to $6.7 \%)$, more in Bihar $(8.5 \%)$. The vaccines stored in non-standard cold chain devices (domestic refrigerators/cold boxes) were exposed to $>8{ }^{\circ} \mathrm{C}$ for $55 \%$ of the observation period.

\section{Continuous episodes of temperature excursion}

The continuous temperature excursion episodes were observed at all levels of VSs, as reflected in Table 3 . The pooled continuous episodes $(\geq 45 \mathrm{~min})$ constituted to $14.8 \%$ of the temperature excursion to the sub-zero temperature ranges. The proportion of continuous excursion episodes were higher in the devices at all levels in Bihar; $13.1 \%$ at state/division, $12.9 \%$ at districts and $19.7 \%$ at sub-district VSs, which were higher than Gujarat and Kerala. The continuous excursion episodes to sub-zero temperature at the sub-district VSs in Gujarat were also high (19.9\%).

As shown in Table 4, the pooled continuous excursion episodes constituted $6.6 \%$ of the temperature excursion duration to $>8{ }^{\circ} \mathrm{C}$ range. The continuous excursion episodes to $>8^{\circ} \mathrm{C}$ were higher in Bihar (6.6\%) than Gujarat and Kerala. The continuous excursion episodes in Bihar were higher at district (25.5\%) followed by state/division (7.4\%) and sub-district level VSs (7.8\%).

\section{Routine temperature monitoring practices}

At the state/division VSs, 76\% of the WICs (Bihar$63.6 \%$, Gujarat-90\% and Kerala-75\%) and $71.4 \%$ of ILRs (Bihar-72.7\%, Gujarat-80\% and Kerala- 61.5\%) had functional temperature monitors at the time of observation. The functional thermometers were available in $83.6 \%$ (Bihar-76.3\%, Gujarat-74.6\% and Kerala-100\%) of ILRs at district VSs and 97\% (Bihar-94.7\%, Gujarat-100\% and Kerala-96.4\%) of ILRS at sub-district VSs. The temperature logbook was available at all state/division, $81.7 \%$ of the district (Bihar-81.8\%, Gujarat-83.3\% and Kerala-80\%) and $84.5 \%$ of the sub-district VSs (Bihar66.5\%, Gujarat-92.6\% and Kerala-94.3\%). From the temperature logbooks, deviation in temperature $\left(<2{ }^{\circ} \mathrm{C} /\right.$ $>8^{\circ} \mathrm{C}$ ) for the observation period (period of logtag installation) was observed in only $5.6 \%$ of devices (Bihar, $n=7$; Gujarat, $n=4$ and Kerala, $n=1$ ). According to the logbooks, deviations in temperature to $<2{ }^{\circ} \mathrm{C}$ or $>8{ }^{\circ} \mathrm{C}$ were observed at $5.8 \%$ facilities (Bihar, $\mathrm{n}=7$; Gujarat, $n=3$ and Kerala, $n=4$ ) during 3 months prior to the survey. Weekly supervision of temperature logbook by the in-charge officer (bearing signature) was observed at $24.1 \%$ facilities and at least one supervision was done at $29.6 \%$ facilities within last 1 month. Gaskets were not fitting/damaged in $23.3 \%$ of the devices and ice layer $>5$ $\mathrm{mm}$ was observed in $2 \%$ ILRs. The documentation for preventive maintenance of the devices were not available at most $(85 \%)$ of the facilities, more at the district and sub-district level.

Frozen freeze sensitive vaccine vials were observed in 12 PHCs in Bihar (from 5 districts), 7 PHCs in Gujarat (from 3 districts) and $6 \mathrm{CHCs} / \mathrm{PHCs}$ in Kerala (from 4 districts). The study team didn't check the all the vaccine vials in the ILRs/WICs for freezing or damage. No vaccine vial was discarded due to freezing or damage at any of the surveyed facilities (VSs) as per the store records.

\section{Discussion}

Immunization is a critical component of the Government of India's child survival strategy, elimination and control of vaccine preventable diseases (maternal and neonatal tetanus, poliomyelitis, measles, etc.) and achieving sustainable development goal of ending preventable deaths of newborn and under-five children by 2030. In 2017, India's immunization budget was estimated to 1480 million USD which has almost doubled compared to 2012 (around 700 million USD). The share of vaccine cost has increased from $11 \%$ in 2012 to $38 \%$ in 2017 (around 560 million USD) with introduction of the new vaccines [20]. Maintenance of optimal cold-chain system across all levels is inevitable to ensure administration of 
Table 2 Temperature integrity in cold chain devices according to type of vaccine stores

\begin{tabular}{|c|c|c|c|c|c|c|c|c|c|}
\hline \multirow[t]{2}{*}{ Levels/ Devices } & \multirow[t]{2}{*}{ State } & \multirow{2}{*}{$\begin{array}{l}\text { Duration }{ }^{a} \\
\text { (hours) }\end{array}$} & \multicolumn{5}{|c|}{$\%$ of time spent } & \multirow{2}{*}{$\begin{array}{l}\text { Average } \\
\text { temp }\left({ }^{\circ} \mathrm{C}\right)\end{array}$} & \multirow{2}{*}{$\begin{array}{l}\text { Temperatur } \\
\text { range }\left({ }^{\circ} \mathrm{C}\right) \\
\text { (min, max) }\end{array}$} \\
\hline & & & $<-3^{\circ} \mathrm{C}$ & $\begin{array}{l}-3^{\circ} \mathrm{C} \text { to } \\
0^{\circ} \mathrm{C}\end{array}$ & $0^{\circ} \mathrm{C}$ to $2^{\circ} \mathrm{C}$ & $2^{\circ} \mathrm{C}$ to $8^{\circ} \mathrm{C}$ & $>8^{\circ} \mathrm{C}$ & & \\
\hline \multicolumn{10}{|c|}{ According to levels of stores } \\
\hline \multirow[t]{4}{*}{ State and Divisions } & Bihar & 4107.5 & 4.5 & 8.6 & 12.8 & 66.6 & 7.4 & 2.7 & $-16.1,26.1$ \\
\hline & Gujarat & 1395 & 0.1 & 0.3 & 11.2 & 86.2 & 1.9 & 4.8 & $-7.2,19.7$ \\
\hline & Kerala & 860.5 & 0 & 0 & 0 & 99.6 & 0.4 & 4.6 & $2.1,33.2$ \\
\hline & Total & 6363 & 2.9 & 5.6 & 10.7 & 75.4 & 5.2 & 3.8 & $-16.1,33.2$ \\
\hline \multirow[t]{4}{*}{ District } & Bihar & 5163.7 & 6.4 & 6.5 & 16.8 & 44.7 & 25.5 & 2.6 & $-22.9,23.9$ \\
\hline & Gujarat & 3228.7 & 0 & 0.1 & 2 & 97.4 & 0.4 & 4.8 & $-1.2,25.3$ \\
\hline & Kerala & 1914.5 & 0 & 1 & 1.1 & 97.9 & 0 & 3.7 & $-1.5,12.8$ \\
\hline & Total & 10,307 & 3.2 & 3.5 & 9.3 & 71.1 & 12.9 & 3.6 & $-22.9,25.3$ \\
\hline \multirow[t]{4}{*}{ Sub-district } & Bihar & $23,728.2$ & 9.6 & 10.1 & 14.5 & 58 & 7.8 & 2.4 & $-33.0,34.9$ \\
\hline & Gujarat & $12,115.2$ & 6.3 & 13.7 & 25.1 & 53.4 & 1.5 & 2.0 & $-14.1,33.3$ \\
\hline & Kerala & 6526.2 & 0 & 6.5 & 36.8 & 53.9 & 2.8 & 2.8 & $-2.6,34.6$ \\
\hline & Total & $42,369.7$ & 7.2 & 10.5 & 21 & 56 & 5.2 & 2.4 & $-33.0,34.9$ \\
\hline \multicolumn{10}{|c|}{ According to type of devices } \\
\hline \multirow[t]{4}{*}{ WIC } & Bihar & 3483.2 & 0.5 & 8.2 & 10.6 & 72 & 8.6 & 4.4 & $-4.6,26.1$ \\
\hline & Gujarat & 1036.7 & 0.1 & 0.4 & 15.1 & 81.5 & 2.5 & 4.6 & $-7.2,19.7$ \\
\hline & Kerala & 718.5 & 0 & 0. & 0 & 99.5 & 0.5 & 4.3 & $2.1,33.2$ \\
\hline & Total & 5238.5 & 0.4 & 5.5 & 10.1 & 77.6 & 6.3 & 4.4 & $-7.2,33.2$ \\
\hline \multirow[t]{4}{*}{ ILR } & Bihar & $28,452.2$ & 9.7 & 9.8 & 14.9 & 56.4 & 9.1 & 1.9 & $-33.0,34.6$ \\
\hline & Gujarat & $15,702.2$ & 4.8 & 10.6 & 19.8 & 63.5 & 1.3 & 2.7 & $-14.1,33.3$ \\
\hline & Kerala & 8582.7 & 0 & 5.1 & 28.2 & 64.5 & 2.1 & 3.0 & $-2.6,33.2$ \\
\hline & Total & $52,737.2$ & 6.7 & 9.3 & 18.5 & 59.9 & 5.6 & 2.4 & $-33.0,34.6$ \\
\hline \multirow[t]{2}{*}{ Other devices ${ }^{b}$} & Bihar & 1064 & 0 & 0.3 & 21.9 & 22.1 & 55.5 & 9 & $-2.3,24.6$ \\
\hline & Total & 1064 & 0 & 0.3 & 21.9 & 22.1 & 55.5 & 9 & $-2.3,24.6$ \\
\hline \multicolumn{10}{|c|}{ Pooled for all levels and all types of devices } \\
\hline \multirow[t]{4}{*}{ Pooled all levels } & Bihar & $32,999.5$ & 8.5 & 9.3 & 14.7 & 57 & 10.5 & 2.4 & $-33.0,34.9$ \\
\hline & Gujarat & 16,739 & 4.5 & 9.9 & 19.5 & 64.6 & 1.4 & 2.8 & $-14.1,33.3$ \\
\hline & Kerala & 9301.2 & 0 & 4.7 & 26 & 67.2 & 2 & 3.2 & $-2.61,34.6$ \\
\hline & Total & $59,039.7$ & 6 & 8.8 & 17.8 & 60.8 & 6.6 & 2.7 & $-33.0,34.9$ \\
\hline
\end{tabular}

WIC Walk-in cooler, ILR Ice lined refrigerator

${ }^{a}$ Duration of temperature recording by data loggers in the cold chain devices in hours

${ }^{b}$ Other devices (domestic refrigerator and cold boxes) were used for vaccine storage in Bihar only at the time of the study

good quality and potent vaccines to each child or woman in the country.

During the observation period, temperature excursion outside +2 to $+8^{\circ} \mathrm{C}$ range was documented for sizable proportion of storage times (24.6 to $43.9 \%$ ) at all levels. Temperature excursions to both extremes of temperature range, $<0^{\circ} \mathrm{C}$ and $>8^{\circ} \mathrm{C}$ were observed at all levels. The vaccines were exposed to continuous episodes of temperature excursion, longer to $<0{ }^{\circ} \mathrm{C}$ range (14.8\%) than to $>8^{\circ} \mathrm{C}$ range $(6.6 \%)$. The exposure to sub-zero temperature at the state/division vaccine stores was worrisome in view of the duration exposure, continuous episodes and bulk storage of vaccines for longer period. The reasons for higher temperature excursions observed in devices in one state (Bihar) were not clearly known.

Another study from India (10 states; 131 facilities) reported exposure of vaccines to $>8{ }^{\circ} \mathrm{C}$ for $8.3-14.7 \%$ $(14.3,13.2,8.3$ and $14.7 \%$ for state, divisional, district and sub-district vaccine stores respectively) and to below $0{ }^{\circ} \mathrm{C}$ for $0.2-10.5 \%$ (1.5, $0.2,0.6$ and $10.5 \%$ for state, divisional, district and sub-district vaccine stores respectively). While state stores in eight states documented excursion to $>8{ }^{\circ} \mathrm{C}$ temperature $(0-83.3 \%)$, only one state (Tamil Nadu) experienced excursion to sub-zero temperature (10.7\%). The exposure to sub-zero 
Table 3 Continuous episodes of temperature excursion below $0^{\circ} \mathrm{C}$ in cold chain devices

\begin{tabular}{|c|c|c|c|c|c|c|c|}
\hline & & \multirow{3}{*}{$\begin{array}{l}\text { Total } \\
\text { observation }_{\text {period }^{\mathrm{a}}}\end{array}$} & \multicolumn{5}{|c|}{ Exposure to temperature $<0^{\circ} \mathrm{C}$} \\
\hline & & & \multirow{2}{*}{$\begin{array}{l}\text { Total } \\
\text { duration } \\
\text { (hours) }\end{array}$} & \multirow{2}{*}{$\begin{array}{l}\text { Total } \\
\text { continuous } \\
\text { episodes } \\
\text { duration } \\
\text { (hours) }\end{array}$} & \multicolumn{3}{|c|}{ Duration of continuous episodes ${ }^{b}$} \\
\hline & & & & & $\leq 1 \mathrm{~h}$ & $>1-9 h$ & $\geq 10 \mathrm{~h}$ \\
\hline \multirow[t]{4}{*}{ State and Division } & Bihar & 4107.5 & 540 & 28.9 & 12.7 & 14 & 2.2 \\
\hline & Gujarat & 1395 & 5.75 & 0.7 & 0.2 & 0.5 & 0 \\
\hline & Kerala & 860.5 & 0 & 0 & 0 & 0 & 0 \\
\hline & Total & 6363 & 545.7 & 29.7 & 13 & 14.5 & 2.2 \\
\hline \multirow[t]{4}{*}{ District } & Bihar & 5163.7 & 666.7 & 5.9 & 0.7 & 2.7 & 2.5 \\
\hline & Gujarat & 3228.7 & 4.5 & 0.7 & 0 & 0.7 & 0 \\
\hline & Kerala & 1914.5 & 19 & 1 & 0 & 1 & 0 \\
\hline & Total & 10,307 & 690.2 & 7.7 & 0.7 & 4.5 & 2.5 \\
\hline \multirow[t]{4}{*}{ Sub-district } & Bihar & $23,728.2$ & 4663.2 & 41.9 & 5.2 & 19 & 17.7 \\
\hline & Gujarat & $12,115.2$ & 2415.7 & 62.9 & 29.2 & 26.2 & 7.5 \\
\hline & Kerala & 6526.2 & 421.2 & 14.9 & 3 & 10.2 & 1.7 \\
\hline & Total & $42,369.7$ & 7500.2 & 120 & 37.5 & 55.5 & 27 \\
\hline \multirow[t]{4}{*}{ WICs } & Bihar & 3483.2 & 303.2 & 22.2 & 12.2 & 8 & 2 \\
\hline & Gujarat & 1036.7 & 5.75 & 0.7 & 0.2 & 0.5 & 0 \\
\hline & Kerala & 718.5 & 0 & 0 & 0 & 0 & 0 \\
\hline & Total & 5238.5 & 309 & 23 & 12.5 & 8.5 & 2 \\
\hline \multirow[t]{4}{*}{ ILRs } & Bihar & $28,452.2$ & 5563.2 & 53.7 & 5.7 & 27.5 & 20.5 \\
\hline & Gujarat & $15,702.2$ & 2420.2 & 63.7 & 29.2 & 27 & 7.5 \\
\hline & Kerala & 8582.7 & 440.2 & 16.4 & 3 & 11.7 & 1.7 \\
\hline & Total & $52,737.2$ & 8423.7 & 133.4 & 38 & 65.7 & 29.7 \\
\hline \multirow[t]{2}{*}{ Other devices ${ }^{c}$} & Bihar & 1064 & 3.5 & 0.9 & 0.7 & 0.2 & 0 \\
\hline & Total & 1064 & 3.5 & 0.9 & 0.7 & 0.2 & 0 \\
\hline \multirow[t]{4}{*}{ Pooled all levels } & Bihar & $32,999.5$ & 5870 & 76.9 & 18.7 & 35.7 & 22.5 \\
\hline & Gujarat & 16,739 & 2426 & 64.5 & 29.5 & 27.5 & 7.5 \\
\hline & Kerala & 9301.2 & 440.2 & 16.4 & 3 & 11.7 & 1.7 \\
\hline & Total & $59,039.7$ & 8736.2 & 157.7 & 51.5 & 74.5 & 31.7 \\
\hline
\end{tabular}

WIC Walk-in cooler, ILR Ice lined refrigerator

a Duration in hours

${ }^{b} \mathrm{~A}$ continuous episode below $0{ }^{\circ} \mathrm{C}$ was counted when readings were continuously below $0{ }^{\circ} \mathrm{C}$ for at least 45 min or more

c Other devices (domestic refrigerator and cold boxes) were used for vaccine storage in Bihar only at the time of the study

temperature (10.5\%) was comparable that for $>8{ }^{\circ} \mathrm{C}$ $(14.7 \%)$ at sub-district stores. Continuous episodes constituted majority of the temperature deviations; about 85 and $94 \%$ of the exposure to temperatures of $<0{ }^{\circ} \mathrm{C}$ and $>$ $8{ }^{\circ} \mathrm{C}$ respectively [15]. The two states (Bihar and Gujarat) were common with the current study. At state/division level stores, the vaccines were exposed to $>8^{\circ} \mathrm{C}$ for 16.6 and $0.5 \%$ of observation periods respectively. In Bihar, at district and sub-district level stores, the vaccines were exposed to $>8{ }^{\circ} \mathrm{C}$ for 49 and $39.5 \%$ of observation periods respectively. No temperature excursion was observed at district levels stores in Gujarat. The vaccines were exposed to sub-zero temperature for 2.6 and $11.6 \%$ of observation period in Bihar and Gujarat respectively. Several other studies also reported temperature integrity challenges at vaccine stores and outreach levels in India [10-12, 21, 22].

Review of articles (14 studies; during 1985-2006) summarized that at storage level, $21.9 \%$ (95\% CI: $10.3-$ $33.6 \%)$ refrigerators in developing countries were exposed to freezing temperature compared to $13.5 \%$ (95\% CI: 6.4-20.7\%) in developed countries [13, 23-25]. A follow up review of articles (18 studies including 8 from developing countries and 10 from developed countries; during 2006-2014) documented that at storage level, $37.1 \%$ (SD: 29.7) of the refrigerators in developing 
Table 4 Continuous episodes of temperature excursion above $8^{\circ} \mathrm{C}$ in cold chain devices

\begin{tabular}{|c|c|c|c|c|c|c|c|}
\hline & & \multirow{3}{*}{$\begin{array}{l}\text { Total } \\
\text { observation } \text { period }^{\mathrm{a}} \\
\text { (hours) }\end{array}$} & \multicolumn{5}{|c|}{ Exposure to temperature $>8^{\circ} \mathrm{C}$} \\
\hline & & & \multirow{2}{*}{$\begin{array}{l}\text { Total } \\
\text { duration } \\
\text { (hours) }\end{array}$} & \multirow{2}{*}{$\begin{array}{l}\text { Total } \\
\text { continuous } \\
\text { episodes } \\
\text { duration }^{\mathrm{a}} \\
\text { (hours) }\end{array}$} & \multicolumn{3}{|c|}{ Duration of continuous episodes ${ }^{b}$} \\
\hline & & & & & $\leq 1 \mathrm{~h}$ & $>1-9 h$ & $\geq 10 h$ \\
\hline \multirow[t]{4}{*}{ State and Divisions } & Bihar & 4107.5 & 302.7 & 14.5 & 4.25 & 8 & 2.25 \\
\hline & Gujarat & 1395 & 26 & 7 & 7 & 0 & 0 \\
\hline & Kerala & 860.5 & 3.5 & 0.2 & 0 & 0.25 & 0 \\
\hline & Total & 6363 & 332.2 & 21.7 & 11.25 & 8.25 & 2.25 \\
\hline \multirow[t]{4}{*}{ District } & Bihar & 5163.7 & 1318.7 & 2.2 & 0 & 0.5 & 1.75 \\
\hline & Gujarat & 3228.7 & 14.5 & 0.5 & 0.25 & 0 & 0.25 \\
\hline & Kerala & 1914.5 & 0.5 & 0.2 & 0.25 & 0 & 0 \\
\hline & Total & 10,307 & 1333.7 & 3 & 0.5 & 0.5 & 2 \\
\hline \multirow[t]{4}{*}{ Sub-district } & Bihar & $23,728.2$ & 1846.2 & 28.5 & 8.75 & 11.75 & 8 \\
\hline & Gujarat & $12,115.2$ & 186 & 6.5 & 4 & 1.2 & 1.2 \\
\hline & Kerala & 6526.2 & 182.7 & 2.2 & 0.5 & 0 & 1.7 \\
\hline & Total & $42,369.7$ & 2215 & 38.2 & 13.5 & 12.7 & 12 \\
\hline \multirow[t]{4}{*}{ WICs } & Bihar & 3483.2 & 299.2 & 13.7 & 3.7 & 8 & 2 \\
\hline & Gujarat & 1036.7 & 26 & 7 & 7 & 0 & 0 \\
\hline & Kerala & 718.5 & 3.5 & 0.2 & 0 & 0.2 & 0 \\
\hline & Total & 5238.5 & 328.7 & 21 & 10.7 & 8.2 & 2 \\
\hline \multirow[t]{4}{*}{ ILRs } & Bihar & $28,452.2$ & 2578 & 27.2 & 9 & 11.2 & 7.5 \\
\hline & Gujarat & $15,702.2$ & 200.5 & 7.5 & 4.5 & 1.2 & 1.5 \\
\hline & Kerala & 8582.7 & 183.2 & 2.5 & 0.7 & 0 & 1.7 \\
\hline & Total & $52,737.2$ & 2961.7 & 37.2 & 14.2 & 12.5 & 10.7 \\
\hline \multirow[t]{2}{*}{ Other devices ${ }^{c}$} & Bihar & 1064 & 590.5 & 4.75 & 0.7 & 0.7 & 3.2 \\
\hline & Total & 1064 & 590.5 & 4.7 & 0.7 & 0.7 & 3.2 \\
\hline \multirow[t]{4}{*}{ Pooled all levels } & Bihar & $32,999.5$ & 3467.7 & 46.2 & 13.5 & 20 & 12.7 \\
\hline & Gujarat & 16,739 & 226.5 & 14.5 & 11.5 & 1.2 & 1.5 \\
\hline & Kerala & 9301.2 & 186.7 & 2.7 & 0.7 & 0.2 & 1.7 \\
\hline & Total & $59,039.7$ & 3881 & 63.2 & 25.7 & 21.5 & 16 \\
\hline
\end{tabular}

WIC Walk-in cooler, ILR Ice lined refrigerator

a Duration in hours

${ }^{b} \mathrm{~A}$ continuous episode above $8{ }^{\circ} \mathrm{C}$ was counted when readings were continuously above $8{ }^{\circ} \mathrm{C}$ for at least 45 min or more

c Other devices (domestic refrigerator and cold boxes) were used for vaccine storage in Bihar only at the time of the study

countries and $33.3 \%$ (SD: 22.5) in developed countries $[14,15,26-28]$. These two reviews indicate persistence of the temperature excursion at the vaccine storage points, despite the possible variations in study methodologies and rigors. The practices of manual temperature monitoring were not able to capture these temperature excursions. According to reports, the practice of detection of freezing by shake test for freeze-sensitive vaccines had been suboptimal, both at vaccine stores $(22.4 \%)$ and vaccination sites $(8.6 \%)[6,21,29]$.

The stability and potency of vaccines are generally temperature-sensitive. Effect of vaccine exposure to higher temperature is usually cumulative and can alter the protein structure and/or chemical stability leading to loss of potency. VVM indicates the cumulative exposure to heat (duration * degree of heat). Exposure of freezesensitive vaccines to sub-zero temperatures cause dissociation of antigen from adjuvants, conglomeration of the aluminium salt adjuvants, and the granule size increase with repeated freeze-thaw cycles $[8,30]$. Administration of frozen DPT and TT vaccines are more likely to cause local reactions [30, 31]. Exposure of DPT vaccines to freeze-thaw cycles have demonstrated progressive drop in potency with number of cycles [32]. Instances of vaccine failure and suboptimal population immunity with vaccination with the frozen freeze- 
sensitive less potent vaccines has been reported for hepatitis B in Mongolia and pertussis in USA [33, 34].

This study documented the temperature integrity and occurrence of excursions at the vaccine stores of all levels in the three states. These temperature excursions were not captured by the routine manual temperature monitoring. The issues emerged that require attention for safe storage of the vaccines were: lack of routine maintenance practices including defrosting, thermostat setting according to ambient temperature, irregular power supply, shortages of trained and dedicated personnel, calibration of thermometers and periodic supervision to ensure cold chain maintenance, especially at the sub-district levels. It may be important to assess the impact of temperature deviations and continuous episodes on freezing and damage of the vaccine vials in the WICs/ILRs in future studies.

The recent efforts of Government of India on Electronic Vaccine Intelligence Network (eVIN) is a step towards ensuring vaccine temperature integrity at cold chain stores [35]. The eVIN system is being expanded in a phased manner in India. Efforts towards training of the cold chain handlers are also being undertaken. Also till eVIN is implemented universally, availability of functional thermometer in all cold chain devices and appropriate documentation are to be ensured. Apart from the stringent temperature monitoring, capacity building of the dedicated cold chain handlers and technicians for routine device maintenance, ensuring appropriate power supply, suitable voltage stabilizers and regular supervision and monitoring are needed to ensure cold chain integrity, especially at the district and sub-district levels.

Our study has certain limitations. We did not use additional freeze alert to indicate freezing. Shake test was not done for all the eligible vaccine vials. Shake test was done for the vaccine vials from the devices only once, at the time of LogTag removal, thus might not inform about the past freezing exposures. The potency of vaccines exposed to either higher or lower temperatures was not tested.

\section{Conclusions}

The study documented that vaccines were exposed to freezing temperature for a considerable period at all level stores and the exposure duration was more than that to the higher temperature. These sub-zero temperature excursions were not captured by the routine manual temperature monitoring and indicated by any VVM like indicator. Exposure of the freeze-sensitive vaccines to sub-zero temperature can affect the vaccine potency and reduce effectiveness. To ensure vaccine potency and immunogenicity, stringent temperature integrity maintenance is needed at all levels. There is need for refresher capacity building of cold chain handlers and store in-charges in preventive device maintenance, ensuring periodic physical audits and systematic supportive supervision.

\section{Abbreviations}

CHC: Community health center; Cl: Confidence interval; DF: Deep freezer; DPT: Diphtheria-pertussis-tetanus; eVIN: Electronic Vaccine Intelligence Network; GMSD: Government medical supply depots; HB: Hepatitis B; Hib: Haemophilus influenza b; HPV: Human papillomavirus; ILR: Ice-lined refrigerator; IPV : Inactivated poliovirus; LMIC: Low and middle income countries; LPV: Liquid pentavalent vaccine; OPV : Oral poliovirus vaccine; PCV: Pneumococcal conjugate vaccine; PHC : Primary health center; SD: Standard deviation; TT: Tetanus toxoid; UIP : Universal immunization program; USD: United States Dollar; WM: Vaccine vial monitor; WHO: World health organization; WIC: Walk-in cooler; WIF: Walk-in freezer

\section{Acknowledgements}

We are grateful to Immunization Division, Government of India, Departments of Health and Family Welfare, Kerala, Gujarat and Bihar for providing the opportunity to undertake this project in the respective states. We highly appreciate the support from the health functionaries and health

administration of the districts in the three states for implementing the project activities. We highly acknowledge the data collection teams from partner medical colleges under leadership of Dr. Ashok Kumar, Darbhanga Medical College, Darbhanga, Bihar; Dr. C B Kumar, Patna Medical College, Patna, Bihar; Dr. Arvind Kumar, S. K. Medical College, Muzaffarpur, Bihar; Dr. Ayan Ghosh, Katihar Medical College, Katihar, Bihar; Dr. Sudha Yadav, M P Shah Medical College, Jamnagar, Gujarat; Dr. V S Mazumdar, Govt. Medical College, Vadodara, Gauarat; Dr. Geeta Kedia, BJ Medical College, Ahmedabad, Gujarat; Dr. S L Kantharia, Government Medical College, Surat, Gujarat; Dr. Uday Shankar Singh, PS Medical College, Karamsad, Gujarat; Dr. A Sobha, Government Medical College, Kottayam, Kerala; Dr. Jose Joseph, Government Medical College, Alappuzha, Kerala; Dr. Thomas Bina, Government Medical College, Kozhikode, Kerala; Dr. C Prabhakumari, Government Medical College, Kozhikode, Kerala; Dr. Sara Varghese, Government Medical College,

Thiruvananthapuram, Kerala; Dr. Lucy Raphel, Government Medical College, Thrissur, Kerala; and Dr. Usha Karunakaran, and Dr. Jayashree A K, Academy of Medical Sciences, Pariyaram, Kerala.

\section{Authors' contributions}

MKD and NKA conceptualised the framework for the study protocol, training, data analysis and interpretation. TM, BV and AY coordinated the field data collection. MKD, SKD and AY analysed the data. MKD wrote the first draft of the manuscript. All authors read, provided critical input and approved the final manuscript.

\section{Funding}

This project was supported by the Bill and Melinda Gates Foundation for funding this project [grant number OPP1041395].

\section{Availability of data and materials}

The data used to support the findings of this study can be obtained from the corresponding author on request.

\section{Ethics approval and consent to participate}

The study protocol was reviewed and approved by INCLEN Ethics Committee (Ref: IIEC 06). There was no personal data collected from any patient or individual under the study.

\section{Consent for publication}

Not applicable.

\section{Competing interests}

The authors declare that there is no competing financial or non-financial interests or conflict of interests.

\section{Author details}

1The INCLEN Trust International, F1/5, Okhla Industrial Area, Phase 1, New Delhi 110020, India. ${ }^{2}$ Department of Community Medicine, Government Medical College, Thiruvananthapuram, Kerala 695011, India. ${ }^{3}$ Department of Pediatrics, M P Shah Medical College, Jamnagar, Gujarat 361008, India. 
Received: 19 December 2019 Accepted: 14 May 2020

Published online: 03 June 2020

\section{References}

1. Center for Disease Control. CDC. Ten great public health achievements United States, ten great achievements — United States. MMWR Morb Mortal Wkly Rep. 1999;48:243-8 Available from: https://www.cdc.gov/ mmwr/preview/mmwrhtml/00056796.htm.

2. Yakum MN, Ateudjieu J, Pélagie FR, Walter EA, Watcho P. Factors associated with the exposure of vaccines to adverse temperature conditions: the case of North West region, Cameroon. BMC Res Notes. 2015:8(1) Available from: http://www.biomedcentral.com/1756-0500/8/277. Cited 1 Mar 2018.

3. Ministry of Health and Family Welfare, Government of India. Immunization Handbook for Medical Officers. New Delhi: Ministry of Health \& Family Welfare Government of India; 2016. Cited 1 Mar 2018.

4. World Health Organisation. WHO vaccine management handbook. Module VMH-E2-01.1. How to monitor temperatures in the vaccine supply chain: World Health Organisation; 2015. Available from: http://apps.who.int/iris/ bitstream/10665/183583/1/WHO_IVB_15.04_eng.pdf. Cited 20 Feb 2018.

5. National Cold Chain Vaccine Management Resource Center (NCCVMRC). National Effective Vaccine Management Assessment, India (2013): National Institute of Health \& Family Welfare, India; 2013. Available from: http://www. itsu.org.in/repository-resources/15.National\%20EVM\%20Assessment\%20-\%2 OUNICEF,\%202013.pdf. Cited 1 Mar 2018.

6. Choudhury SA, Ojah J. A study on knowledge and practice of immunization services among auxiliary nurse midwives of subcentre at Chirang district. Assam J Evid Based Med Healthc. 2016;3(16):618-21.

7. World Health Organization. Temperature sensitivity of vaccines. Geneva: World Health Organization; 2006. Available from: https://apps.who.int/iris/ handle/10665/69387.

8. Kartoglu Ü, Özgüler NK, Wolfson LJ, Kurzatkowski W. Validation of the shake test for detecting freeze damage to adsorbed vaccines. Bull World Health Organ. 2010;88(8):624-31

9. Unicef. National cold chain assessment India (2014). India: Unicef, Country Office; 2014. Available from: http://www.nccvmtc.org/PDF1/UNICEF_Cold\%2 OChain\%20Assessment\%20Book.pdf. Cited 1 Mar 2018.

10. Samant $Y$, Lanjewar H, Parker D, Block L, Tomar GS, Stein B. Evaluation of the cold-chain for oral polio vaccine in a rural district of India. Public Health Rep Wash DC 1974. 2007:122(1):112-21.

11. Galhotra A, Goel NK, Pathak R, Kumar R, Swami HM. Surveillance of cold chain system during intensified pulse polio programme--2006 in Chandigarh. Indian J Pediatr. 2007;74(8):751-3.

12. Goel NK, Pathak R, Galhotra A, Dankal C, Swami HM. Status of cold-chain maintenance in Chandigarh. Indian J Public Health. 2008;52(1):37-9.

13. Matthias DM, Robertson J, Garrison MM, Newland S, Nelson C. Freezing temperatures in the vaccine cold chain: a systematic literature review. Vaccine. 2007:25(20):3980-6.

14. Hanson CM, George AM, Sawadogo A, Schreiber B. Is freezing in the vaccine cold chain an ongoing issue? A literature review. Vaccine. 2017. 35(17):2127-33.

15. Murhekar MV, Dutta S, Kapoor AN, Bitragunta S, Dodum R, Ghosh P, et al. Frequent exposure to suboptimal temperatures in vaccine cold-chain system in India: results of temperature monitoring in 10 states. Bull World Health Organ. 2013;91(12):906-13.

16. Ministry of Health and Family Welfare (MOHFW), ORG Centre for Social Research (ORG CSR), United Nations Children's Fund (UNICEF). India coverage evaluation survey: United Nations Children's Fund (UNICEF); 2009. Available from: http://www.indiaenvironmentportal.org.in/files/National Factsheet_30_August_no_logo.pdf. Cited 12 Apr 2013.

17. World Health Organization. Study protocol for temperature monitoring in the vaccine cold chain. Geneva: World Health Organization. Department of Immunization, Vaccines and Biologicals. World Health Organization; 2011. Available from: http://www.who.int/iris/handle/10665/70752.

18. LogTag Recorders. LogTag ${ }^{\oplus}$ TRIX-8 Data logger. Bell Technology Ltd. Available from: http://www.belltechnology.co.nz/Dataloggers/Resources/ LOGTAG_TRIX-8_PRODUCT_SPECIFICATION.pdf. Cited 2 Mar 2018.

19. Boras C, Hanlon M, Gold M, Robertson D. Storage at -3 degrees $C$ for 24 hours alters the immunogenicity of pertussis vaccines. Vaccine. 2001;19(2526):3537-42.
20. Chatterjee S, Pant M, Haldar P, Aggarwal M, Laxminarayan R. Current costs \& projected financial needs of India's universal immunization programme. Indian J Med Res. 2016;143(6):801.

21. Rao S, Naftar S, Baliga S, Unnikrishnana B. Evaluation, awareness, practice and management of cold chain at the primary health care centers in coastal South India. J Nepal Paediatr Soc. 2012;32(1) Available from: http:// nepjol.info/index.php/JNPS/article/view/5946. Cited 3 Mar 2018.

22. Pakhare A, Bali S, Pawar R, Lokhande G. Assessment of cold-chain maintenance in vaccine carriers during Pulse Polio National Immunization Day in a rural block of India. WHO South-East Asia J Public Health. 2014;3(2): 190.

23. Hanjeet K, Lye MS, Sinniah M, Schnur A. Evaluation of cold chain monitoring in Kelantan. Malaysia Bull World Health Organ. 1996;74(4):391-7.

24. Bell KN, Hogue CJ, Manning C, Kendal AP. Risk factors for improper vaccine storage and handling in private provider offices. Pediatrics. 2001;107(6):E100

25. Gazmararian JA, Oster NV, Green DC, Schuessler L, Howell K, Davis J, et al. Vaccine storage practices in primary care physician offices: assessment and intervention. Am J Prev Med. 2002;23(4):246-53.

26. Techathawat $S$, Varinsathien $P$, Rasdjarmrearnsook A, Tharmaphornpilas $P$. Exposure to heat and freezing in the vaccine cold chain in Thailand. Vaccine. 2007;25(7):1328-33.

27. Carr C, Julie B. Durrheim. Practice nurses best protect the vaccine cold chain in general practice. Austr J Adv Nurs. 2009;27(2):35-9.

28. Adeel A, Syed BSN, Azfar I, Osama S. Temperature monitoring of vaccines' storage compartments in different health centres and pharmacies at Karachi. Pak Int J. 2014;5(3):984-8.

29. National Cold Chain Vaccine Management Resource Center (NCCVMRC). National effective vaccine management assessment, India (2013): National Institute of Health \& Family Welfare; 2013. Available from: http://www.itsu. org.in/repository-resources/15.National\%20EVM\%20Assessment\%20-\%2 OUNICEF,\%202013.pdf Cited 20 Feb 2018.

30. Milstien J, Kartoglu U, Zaffran M. Temperature sensitivity of vaccines: World Health Organisation; 2006. Available from: http://apps.who.int/iris/ bitstream/10665/69387/1/WHO_IVB_06.10_eng.pdf. Cited 3 Mar 2018.

31. Hibbs BF, Miller E, Shi J, Smith K, Lewis P, Shimabukuro T. Safety of vaccines that have been kept outside of recommended temperatures: reports to the vaccine adverse event reporting system (VAERS), 2008-2012. Vaccine. 2018;36(4):553-8.

32. PATH. Effects of freezing on vaccine potency. Literature review: PATH; 2003. Available from: https://www.path.org/publications/files/TS_cc_effects.pdf. Cited 3 Mar 2018

33. Davaalkham D, Ojima T, Wiersma S, Lkhagvasuren T, Nymadawa P, Uehara R, et al. Administration of hepatitis $B$ vaccine in winter as a significant predictor of the poor effectiveness of vaccination in rural Mongolia: evidence from a nationwide survey. J Epidemiol Community Health. 2007 61(7):578-84.

34. McColloster P, Vallbona C. Graphic-output temperature data loggers for monitoring vaccine refrigeration: implications for pertussis. Am J Public Health. 2011;101(1):46-7.

35. Ministry of Health and Family Welfare, United Nations Development Program. Improving efficiency of vaccination systems in multiple states. United Nations Development Program. Available from: http://www.in.undp. org/content/india/en/home/operations/projects/health/evin.html. Cited 28 Apr 2018.

\section{Publisher's Note}

Springer Nature remains neutral with regard to jurisdictional claims in published maps and institutional affiliations. 